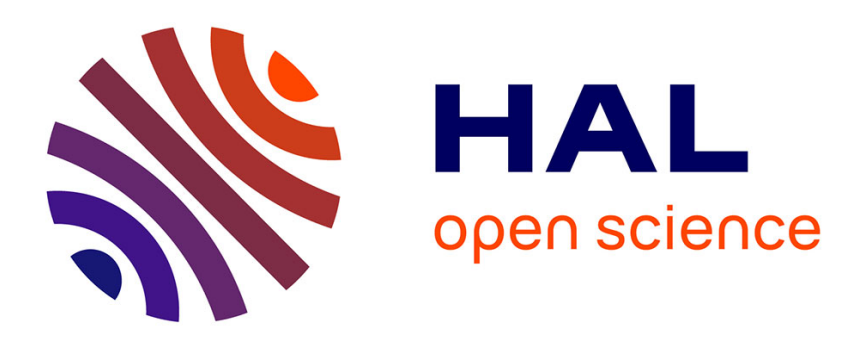

\title{
Le rôle des autorités organisatrices de transport régional en France face aux enjeux européens
}

\author{
David Herrgott
}

\section{To cite this version:}

David Herrgott. Le rôle des autorités organisatrices de transport régional en France face aux enjeux européens. RTS - Recherche Transports Sécurité, 2015, 2015 (02), pp.65-82. 10.4074/S0761898015002010 . hal-01670608

\section{HAL Id: hal-01670608 \\ https://hal.science/hal-01670608}

Submitted on 21 Dec 2017

HAL is a multi-disciplinary open access archive for the deposit and dissemination of scientific research documents, whether they are published or not. The documents may come from teaching and research institutions in France or abroad, or from public or private research centers.
L'archive ouverte pluridisciplinaire $\mathbf{H A L}$, est destinée au dépôt et à la diffusion de documents scientifiques de niveau recherche, publiés ou non, émanant des établissements d'enseignement et de recherche français ou étrangers, des laboratoires publics ou privés. 


\title{
Le rôle des autorités organisatrices de transport régional en France face aux enjeux européens
}

\author{
The role of the public transport regional authorities in France in front of European issues
}

\author{
David Herrgott \\ Reçu le 10 février 2014 ; accepté le 5 novembre 2014 \\ (C) IFSTTAR et Éditions NecPlus 2015
}

Résumé Dans une partie des États membres de l'Union européenne, les régions sont compétentes pour l'organisation des services ferroviaires régionaux de voyageurs. Le concept d'autorité organisatrice de transport est transcrit dans le droit européen. Il permet aux collectivités locales, généralement de niveau régional, de développer des services de transport ferroviaire sur leurs territoires, pour lesquels un opérateur n'assumerait pas le service sans contrepartie.

Dans ce contexte, les réformes européennes et la proposition législative du quatrième paquet ferroviaire visent à « compléter l'espace ferroviaire unique européen », afin de développer son activité en "injectant dans le monde ferroviaire une dose de concurrence et d'innovation pour permettre aux transports ferroviaires nationaux de se moderniser ». Ces réformes, qui auront pour objectif le renforcement des prérogatives des autorités compétentes en matière de transport, se heurtent à la diversité des structures politiques des États membres et de leurs systèmes ferroviaires respectifs.

L'objectif de cet article est de mettre en perspective les positions officielles des autorités organisatrices de transport en charge des services ferroviaires régionaux de voyageurs en France et en Europe par rapport aux enjeux européens. Il balaye le positionnement des autorités organisatrices de transport régional, au regard de la diversité des compétences qui leur sont accordées au sein des États membres, et s'interroge sur la pertinence de l'aboutissement d'un espace ferroviaire unique européen face à la mosaïque des compétences accordées aux collectivités locales pour l'organisation de leurs services ferroviaires.

\footnotetext{
David Herrgott $(\bowtie)$

Doctorant au Laboratoire Image, Ville Environnement (LIVE), Université de Strasbourg, en contrat CIFRE avec le Groupement des Autorités Responsables de Transport (GART) entre 2011 et 2014 e-mail : david@herrgott.fr

Présentée au symposium international «L'espace ferroviaire unique européen, quelle(s) réalité(s) ? », organisé par l’Université de Valenciennes les 26 et 27 septembre 2013.
}

Mots clés autorités organisatrices de transport, OSP, services ferroviaires régionaux de voyageurs, $\mathrm{SNCF}$, transports ferroviaires

Abstract In some Member States of the European Union, Regions are responsible for organizing regional rail passenger services. This concept of public transport authority is transcribed into European law. It allows local authorities, usually on the regional level, to develop rail services in their areas, where an operator does not assume the service without subsidies.

In this context, the European reforms and the legislative proposal of the fourth railway package aims to "complete the European railway single area by injecting in the railway system a dose of competition and innovation in order to modernize national railway". These reforms, which will strength public authorities competences, come up against the diversity of the political structure of the Member States and their rail systems.

The objective of this article is to put into perspective the position of transport authorities in charge of regional rail passenger services in France and Europe compared to European issues. Then, this article examines the relevance of the result of a single European railway facing to the mosaic of competences granted to public transport authorities for the organization of their rail services.

Keywords PSO, Public transport authorities, Railway, Regional trains, SNCF

\section{Introduction}

La prise en compte du rôle des Autorités organisatrices de transport (AOT) pour l'organisation de services ferroviaires de voyageurs est récente dans la législation européenne. Dans son livre blanc La politique européenne des transports à l'horizon 2010 : l'heure des choix [1], la Commission européenne souligne la nécessité "d'éliminer les disparités entre les entreprises de transport des différents États membres, de nature à fausser substantiellement les 
conditions de concurrence », mais ne précise pas le rôle des autorités organisatrices de transport régional. Si les premières approches des réformes européennes visaient à une logique de coopération entre monopoles nationaux, le glissement vers une logique d'ouverture concurrentielle des marchés ferroviaires l'emporte après le renforcement des pouvoirs du Parlement européen et le basculement libéral de ce dernier aux élections de juin 1999 [2].

Il faut attendre la définition du règlement $\mathrm{n}^{\circ}$ 1370/2007 du Parlement européen et du Conseil du 23 octobre 2007 relatif aux services publics de transport de voyageurs par chemin de fer et par route, dit règlement d'Obligations de service public (OSP), pour définir l'" autorité locale compétente », toute autorité compétente dont le périmètre n'est pas national. Le règlement OSP reconnaît ainsi que « de nombreux services de transports terrestres de voyageurs représentant une nécessité d'intérêt économique général n'offrent pas de possibilité d'exploitation commerciale ». L'autorité compétente a la faculté d'intervenir dans une zone géographique donnée, afin d'assurer les services de transport de voyageurs pour lesquels un opérateur n'assumerait pas le service sans contreparties financières.

En France, comme dans de nombreux pays européens, la région devient compétente pour l'organisation de services ferroviaires régionaux de voyageurs, prolongeant à l'échelle et à la portée des réseaux ferroviaires les logiques de déplacements métropolitains et des transports du quotidien [3]. Ainsi, à l'instar des transports urbains, cette évolution a des conséquences sur le plan financier et organisationnel. La Commission européenne rappelle en 2007 que « le concours financier de toutes les parties prenantes, y compris des utilisateurs, aux niveaux local, régional, national et communautaire est nécessaire » pour le financement du transport local [4]. En France, l'expérience, suivie de trente ans de décentralisation, des autorités organisatrices de transport urbaines et métropolitaines contribue au développement des compétences et moyens d'intervention des régions [6].

Les réformes européennes visent à « compléter l'espace ferroviaire unique européen », qui repose sur une infrastructure de réseau intégrée et des équipements interopérables favorables à l'efficacité des services de transport dans toute 1'Union européenne [2]. Les trois paquets ferroviaires, successivement proposés par la Commission européenne entre 2001 et 2007, introduisent progressivement les notions de concurrence et de séparation verticale entre entreprises ferroviaires et gestionnaires de l'infrastructure. Un quatrième paquet a été proposé par la Commission européenne en janvier 2013. Il comporte deux volets relatifs à la sécurité et l'interopérabilité, ainsi qu'un volet sur la gouvernance et l'ouverture à la concurrence.

Plus précisément, la Commission européenne propose d'une part de modifier la directive 2012/34 du Parlement européen et du Conseil du 21 novembre 2012 relative à la refonte du premier paquet ferroviaire, dite directive du recast, afin de supprimer toute limitation d'accès au marché des services ferroviaires nationaux de passagers des États membres [7]. D'autre part, la proposition de refonte du règlement $\mathrm{OSP}$ va principalement généraliser le principe d'adjudication pour les services ferroviaires régionaux de voyageurs dès le 2 décembre 2019 [8]. Elle renforce également les prérogatives des autorités compétentes en imposant la création de plans de transports relatifs à l'exploitation de leurs services, et prévoit un accès réel et non discriminatoire à du matériel ferroviaire.

Ces dispositions prennent source dans la récente feuille de route pour un espace européen unique des transports [9] : « ouvrir le marché intérieur du transport ferroviaire de passagers à la concurrence, y compris par l'obligation d'attribuer les contrats de service public dans le cadre d'appels d'offres concurrentiels ». Pour la Commission européenne, les études d'impacts relatives aux propositions législatives du quatrième paquet ferroviaire aboutissent à la conclusion que l'ouverture à la concurrence permettrait une optimisation des fonds publics destinés au ferroviaire, estimés à 46 milliards d'euros, rien que pour les services conventionnés de voyageurs [10].

Cet article a pour objectif de mettre en perspective les propositions législatives du quatrième paquet ferroviaire, au regard des positions officielles des AOT régionales et de leurs compétences accordées par les différents États membres. Une première partie de l'article s'interroge sur les modalités poussant les États membres à reconnaître l'existence de ces autorités. La seconde partie met en perspective les évolutions législatives européennes face à la « mosaïque institutionnelle » [11] que forment les diverses AOT régionales en Europe.

En effet, le quatrième paquet ferroviaire va répondre à de nombreuses revendications des AOT régionales en France [12] et en Europe. Pour autant, la lecture et l'interprétation des propositions de refonte du règlement $\mathrm{OSP}$ et de modification de la directive du recast peuvent remettre en cause le degré d'intervention des autorités organisatrices de transport régional. Ainsi, leurs compétences et positionnements sont étudiés à partir de dialogues croisés et des prises de positions officielles (figure 1) de leurs organisations représentatives à l'échelle européenne [13, 14, 15], et également au sein des pays où elles sont les plus représentées : Allemagne, France $[16,17,18]$, Italie, Pologne et République Tchèque [19].

Plus précisément, la procédure de lobbying autour de la procédure législative s'est déroulée du 30 janvier 2013 lors de la proposition législative de la Commission européenne jusqu'au 25 février 2014 lors du vote du Parlement européen. La phase de trilogues a ensuite pour objectif d'accorder les trois instances européennes - la Commission, le Parlement et le Conseil - sur une 


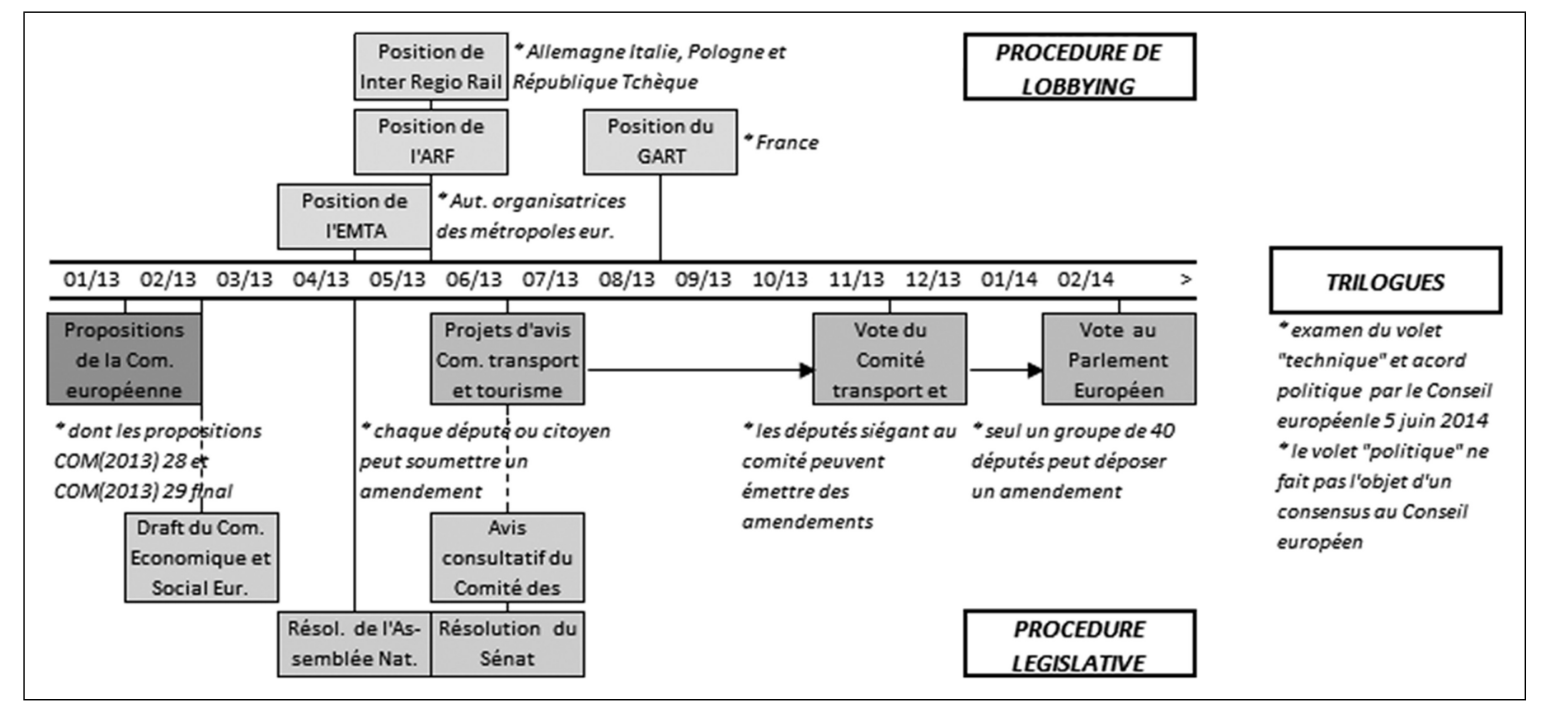

Fig. 1 Matériel utilisé pour l'étude du positionnement des autorités organisatrices de transport régional et des propositions législatives du quatrième paquet ferroviaire

proposition consensuelle. Elle ne traduit aucunement une hiérarchie entre la proposition initiale de la Commission européenne et les amendements des eurodéputés, et ne permet pas de conclure sur l'évolution des relations entre les textes européens et les AOT régionales.

\section{La notion d'autorité organisatrice de transport des services ferroviaires de voyageurs en France et en Europe}

Cette première partie a pour objectif de préciser la définition de l'autorité organisatrice de transport des services ferroviaires régionaux de voyageurs, en s'interrogeant sur les modalités poussant les États membres à les reconnaître.

\section{A. Quelle définition des services ferroviaires de voyageurs?}

En France, comme dans le reste de l'Europe, les services ferroviaires de voyageurs peuvent être distingués selon la portée géographique de leurs dessertes [20]. Cette distinction traduit également les deux types d'organisation du marché ferroviaire décrits par les textes européens : les services «sur le marché », sous la régulation d'un marché libre et concurrentiel ; et les services «pour le marché », sous le régime des obligations de service public [21]. L'équilibre économique de ces services n'est assuré que par des subventions d'équilibre de la part des autorités organisatrices, principalement à l'échelle régionale. Dans ce cadre, la contribution publique aux services ferroviaires régionaux de voyageurs représente en France en moyenne $70 \%$ du coût du transport [22].
Ainsi, en France, bien que la Loi du 30 décembre 1982 d'orientation des transports intérieurs (dite LOTI) impose l'exploitation des services ferroviaires de voyageurs d'intérêt national et régional par l'entreprise ferroviaire historique SNCF, le législateur consacre les « services ferroviaires régionaux de voyageurs » comme services conventionnés sous l'autorité des régions depuis le $1^{\text {er }}$ janvier 2002 [23].

Les conventions de service public à l'échelle nationale, telle que la convention des trains d'équilibre du territoire en France, restent des exceptions, bien que la problématique $\mathrm{du}$ financement des services grandes lignes interroge de nombreux pays européens. En Espagne, l'opérateur ferroviaire historique RENFE met en œuvre un plan de rationalisation de ses 120 dessertes media distancia [24]. Seule l'Autriche dispose d'un conventionnement spécifique à l'échelle nationale [25]. D'autres pays, comme les Pays-Bas, ont mis en œuvre des obligations de service public nationales sans ouvrir leur marché pour autant.

La diversité de la géographie des pays européens et des organisations administratives ne permet pas de distinguer une typologie des services ferroviaires régionaux de voyageurs. Toutefois, en analysant les trafics des plus importants réseaux européens ${ }^{1}$, on observe qu'environ $42 \%$ des passagers-kilomètres sont effectués à bord de trains régionaux.

\footnotetext{
${ }^{1}$ Analyse de l'auteur à partir des rapports annuels des entreprises ferroviaires sur l'année 2009, complétée avec les données Eurostat sur la fréquentation des réseaux en Autriche, Allemagne, Belgique, Danemark, Espagne, Finlande, France, Hongrie, Italie, Pologne, Portugal, République tchèque, Roumanie, Royaume-Uni et Suède, soit 369 milliards de passagers-kilomètres/an sur les 385 milliards de passagers-kilomètres/an dans toute l'UE.
} 
Une part non négligeable des services ferroviaires concerne les transports du quotidien. À ce titre, s'ils ne représentent que $27 \%$ des voyageurs-kilomètres en France (du fait du poids du réseau de trains à grande vitesse), les services ferroviaires régionaux de voyageurs représentent près de la moitié des trains-kilomètres parcourus, et par conséquent près de la moitié du chiffre d'affaires du gestionnaire de l'infrastructure.

\section{B. Quelle présence des AOT au sein des États membres?}

En France, la notion d'AOT vise l'État et les collectivités territoriales, qui dans leurs compétences et périmètres respectifs, organisent des services de transport de voyageurs [26]. La région est ainsi chargée de l'organisation des services ferroviaires régionaux de personnes, ce qui inclut la définition du service des trains régionaux et ses dessertes, la tarification, la qualité du service et l'information de l'usager.

Toutefois, les régions défendent également un accroissement des moyens d'exercice de leurs compétences en matière d'exploitation des Transports express régionaux (TER) [12]. En effet, ces dernières ne disposent actuellement ni de la propriété du matériel roulant, liée à l'entreprise ferroviaire historique d'ici la mise en application de la réforme ferroviaire en décembre 2014, ni de la possibilité de fixer leurs tarifications en dehors des barèmes kilométriques fixés par l'État.

La notion d'autorité locale compétente ne recouvre pas forcément le fait régional à l'échelle de l'Union européenne ${ }^{2}$ (figures 2 et 3 ).

Dans quatorze États membres de l'Union européenne, la Belgique, la Bulgarie, la Croatie, le Danemark, l'Estonie, la Grèce, la Hongrie, l'Irlande, la Lituanie, le Luxembourg, le Portugal, la Roumanie, la Slovaquie et la Slovénie, l'État est l'autorité compétente des services ferroviaires régionaux de voyageurs, dont l'existence n'est pas forcément reconnue en tant que tel.

Inversement, 153 autorités organisatrices de transport des services ferroviaires régionaux existent au sein de douze États membres. Sept États membres ont transféré la compétence des services ferroviaires régionaux de voyageurs aux collectivités locales régionales en France, en Italie, en Pologne, en République Tchèque et en Suède, et aux collectivités locales régionales et urbaines le cas échéant en Allemagne et aux Pays-Bas.

Cinq États membres font figure d'exception, D'une part, ils mixent la présence d'autorités compétentes étatique et

\footnotetext{
${ }^{2}$ L'étude ne porte que sur vingt-six États membres, Chypre et Malte ne disposant pas de réseau ferroviaire. Les cartographies incluent la Suisse pour information, mais ne sont pas prises en compte dans les calculs de l'article.
}

régionale en Autriche (où les compétences des services ferroviaires régionaux de voyageurs sont partagées entre les provinces et l'État), en Espagne (où seule la Catalogne dispose de cette compétence) et au Royaume-Uni (où seuls l'Écosse, l'Irlande du Nord et les Pays de Galles disposent de cette compétence). D'autre part, ils reconnaissent la présence d'autorités compétentes urbaines alors même que l'État conserve la compétence de l'ensemble des services ferroviaires en Finlande (à Helsinki uniquement) et en Lettonie (dans le district de Gulbene uniquement).

\section{Quels facteurs explicatifs ?}

Le volume des marchés domestiques permet partiellement d'expliquer l'existence d'autorités organisatrices de transport des services ferroviaires régionaux de voyageurs (figure 4). Ainsi, les États membres, comptabilisant plus de dix milliards de passagers-kilomètres en trafic domestique, disposent tous d'autorités organisatrices de transport pour les services ferroviaires régionaux de voyageurs, à l'exception du Royaume-Uni dont les franchises sont directement sous la compétence de l'État. Inversement, les États membres comptabilisant moins de cinq milliards de passagers-kilomètres en trafic domestique conservent une autorité compétente étatique pour les services ferroviaires régionaux de voyageurs, à l'exception de la Finlande et de la Lettonie pour deux agglomérations particulières.

La situation est plus contrastée pour les États membres comptabilisant entre cinq et dix milliards de passagerskilomètres en trafic domestique. Le Danemark, la Hongrie et la Roumanie conservent une autorité compétente étatique pour les services ferroviaires régionaux de voyageurs tandis que l'Autriche et la République Tchèque disposent d'autorités organisatrices de transport régional. La Belgique fait également figure d'exception, avec près de neuf milliards de passagers-kilomètres en trafic domestique ; elle est le plus important des États membres sans autorité organisatrice de transport régional, la SNCB étant historiquement considérée comme un service public marqueur de cohésion nationale [27].

Le type de régionalisation observé au sein des États membres [28] pourrait également être corrélé à l'existence d'autorités organisatrices de transport des services ferroviaires régionaux (figure 5).

On peut tout d'abord distinguer en Europe un processus de régionalisation administrative, avec la mise en place par l'État d'institutions subordonnées au gouvernement dont les fonctions visent plus ou moins au développement économique régional en disposant d'une relative autonomie juridique. Ce processus de régionalisation caractérise principalement l'organisation administrative de la Bulgarie, la Croatie, l'Estonie, la Grèce, la Lettonie, la Lituanie, le 


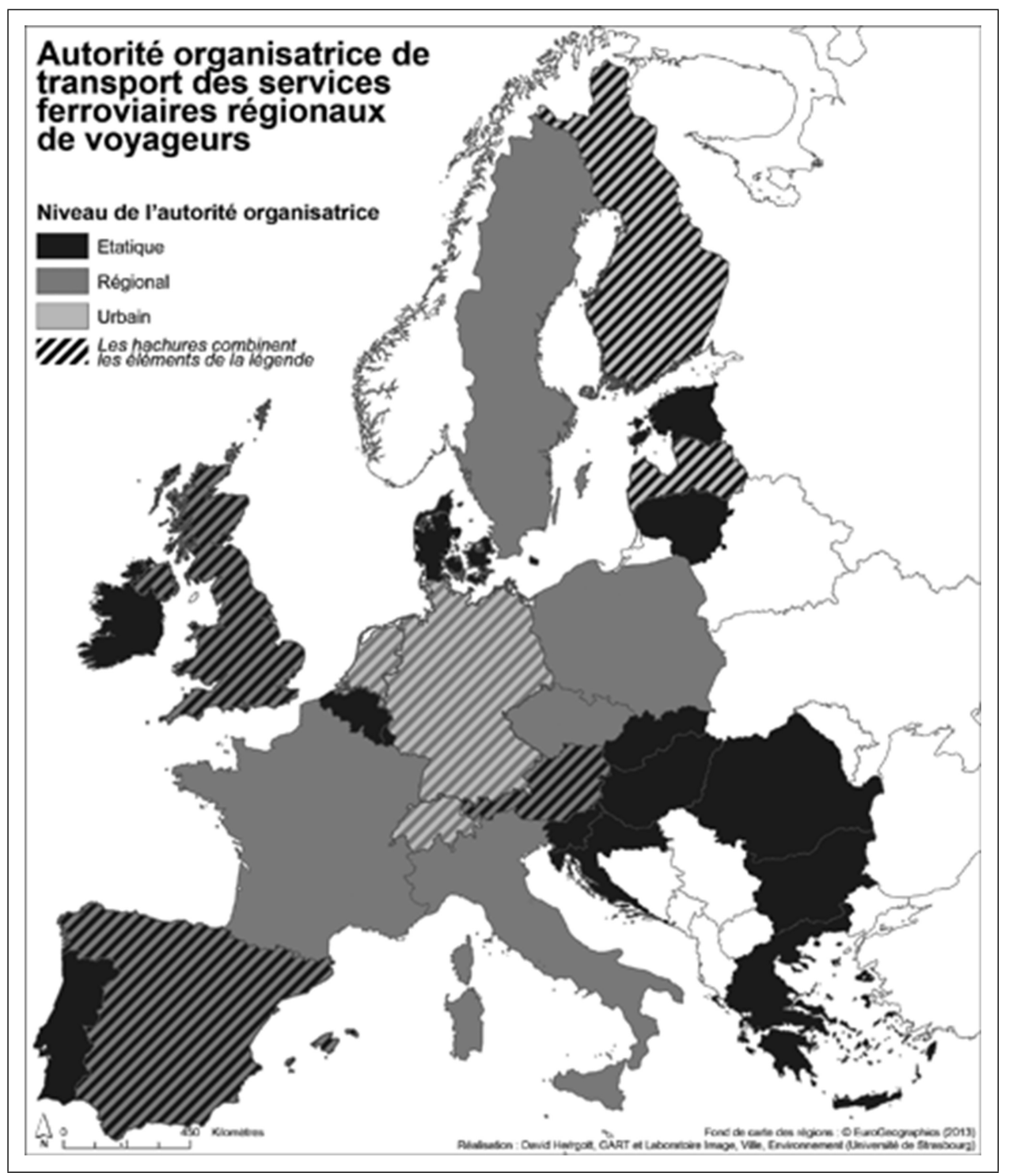

Fig. 2 et 3 Cartographie des autorités organisatrices de transport des services ferroviaires régionaux de voyageurs (travaux de l'auteur)

Luxembourg, le Portugal, le Royaume-Uni, la Slovaquie et de la Slovénie. Aucun de ces pays ne reconnaît pleinement la compétence des autorités organisatrices de transport pour l'exploitation des services ferroviaires régionaux de voyageurs.

Par ailleurs, on peut distinguer les processus de régionalisation politique et de décentralisation régionale où les institutions existantes et/ou mises en place agissent dans le cadre de leurs pouvoirs propres. Ainsi, les huit États membres reconnaissant pleinement la compétence des autorités organisatrices de transport pour l'exploitation des services ferroviaires régionaux de voyageurs - l'Allemagne, l'Autriche, la France, l'Italie, les Pays-Bas, la Pologne, la République tchèque et la Suède - ont tous enclenché un processus de régionalisation visant à une relative autonomie de leurs institutions locales. Seuls la Belgique, le Danemark, l'Espagne (à l'exception de la région de Catalogne) et la Finlande (à l'exception de la région de la capitale Helsinki) ne reconnaissent pas la compétence des services ferroviaires régionaux de voyageurs auprès de leurs collectivités locales.

\section{L'autorité organisatrice de transport des services ferroviaires régionaux de voyageurs à l'épreuve des propositions législatives du quatrième paquet ferroviaire}

Cette seconde partie a pour objectif de mettre en perspective les propositions législatives du quatrième paquet ferroviaire, au regard des positions officielles des AOT régionales et de 


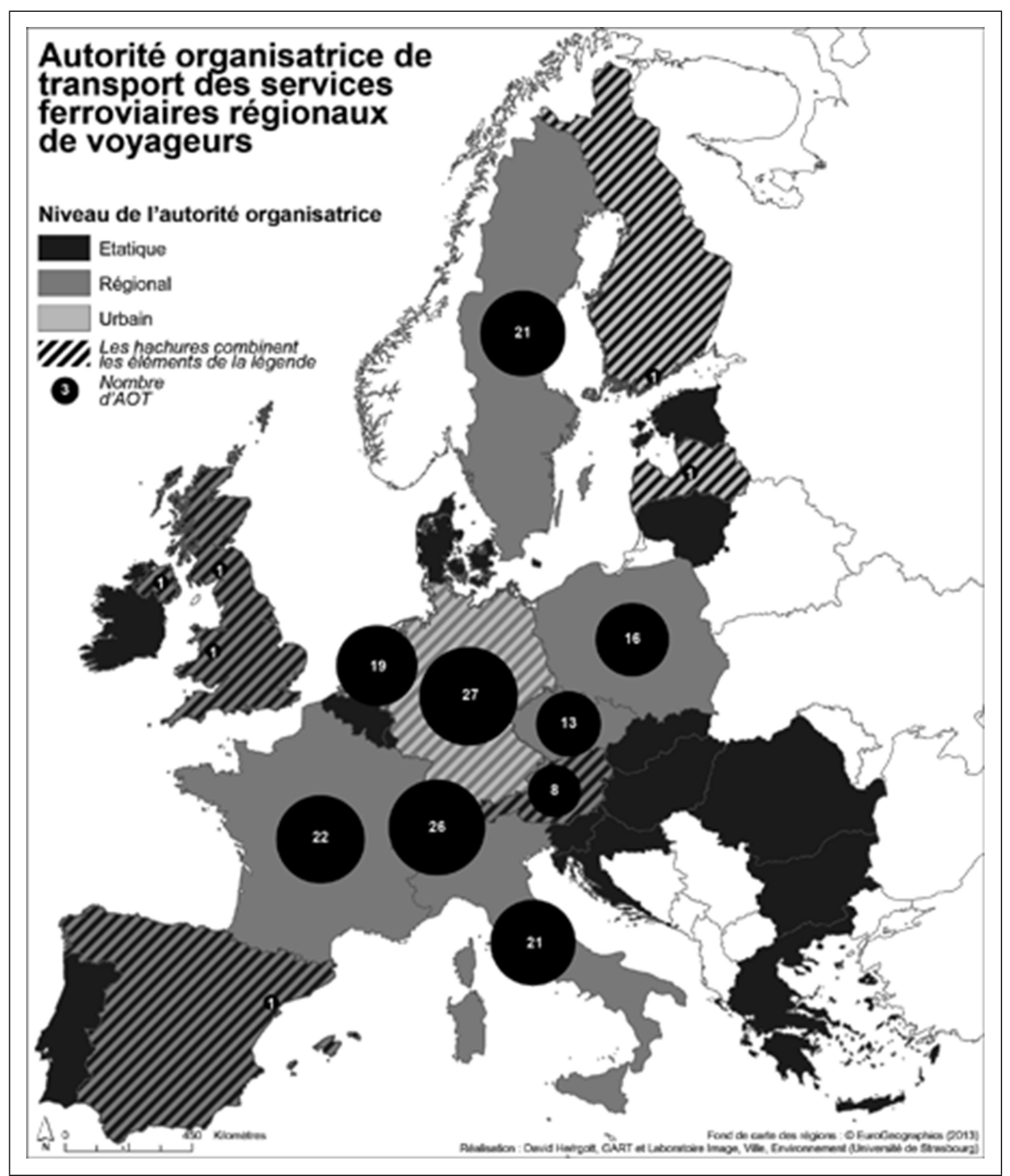

Fig. 2 et 3 (Continued)

leurs compétences accordées par les douze États membres reconnaissant leur existence.

Les propositions législatives de quatrième paquet ferroviaire faites par la Commission européenne le 30 janvier 2013 ont pour objectif : de refondre le règlement $n^{\circ} 1370 / 2007$ du 23 octobre 2007 relatif aux services publics de transports de voyageurs par chemin de fer et par route, dit règlement OSP (proposition de règlement COM(2013) 28 final); de modifier la directive 2012/34 du 21 novembre 2012 relative à la refonte du premier paquet ferroviaire, dite directive du recast (proposition de directive COM(2013) 29 final). Ces deux textes ont été examinés et amendés le 25 février 2014 par le Parlement européen.

Ces textes modifient le périmètre des obligations de service public, notamment par la définition de l'autorité compétente et des effets de seuil en termes de trafic. Ils déterminent également le champ d'intervention des autorités compétentes, ainsi que leurs places dans la gouvernance des systèmes ferroviaires des États membres.

\section{A. Quels périmètres ?}

L'article 2 point c de la proposition de refonte du règlement OSP complète la notion d'autorité locale compétente : " toute autorité compétente dont la zone géographique de compétence n'est pas nationale », en précisant qu'elle « couvre les besoins en transport d'une agglomération urbaine ou d'une localité rurale ». Cette nouvelle définition de l'autorité locale compétente pourrait pénaliser les 63 


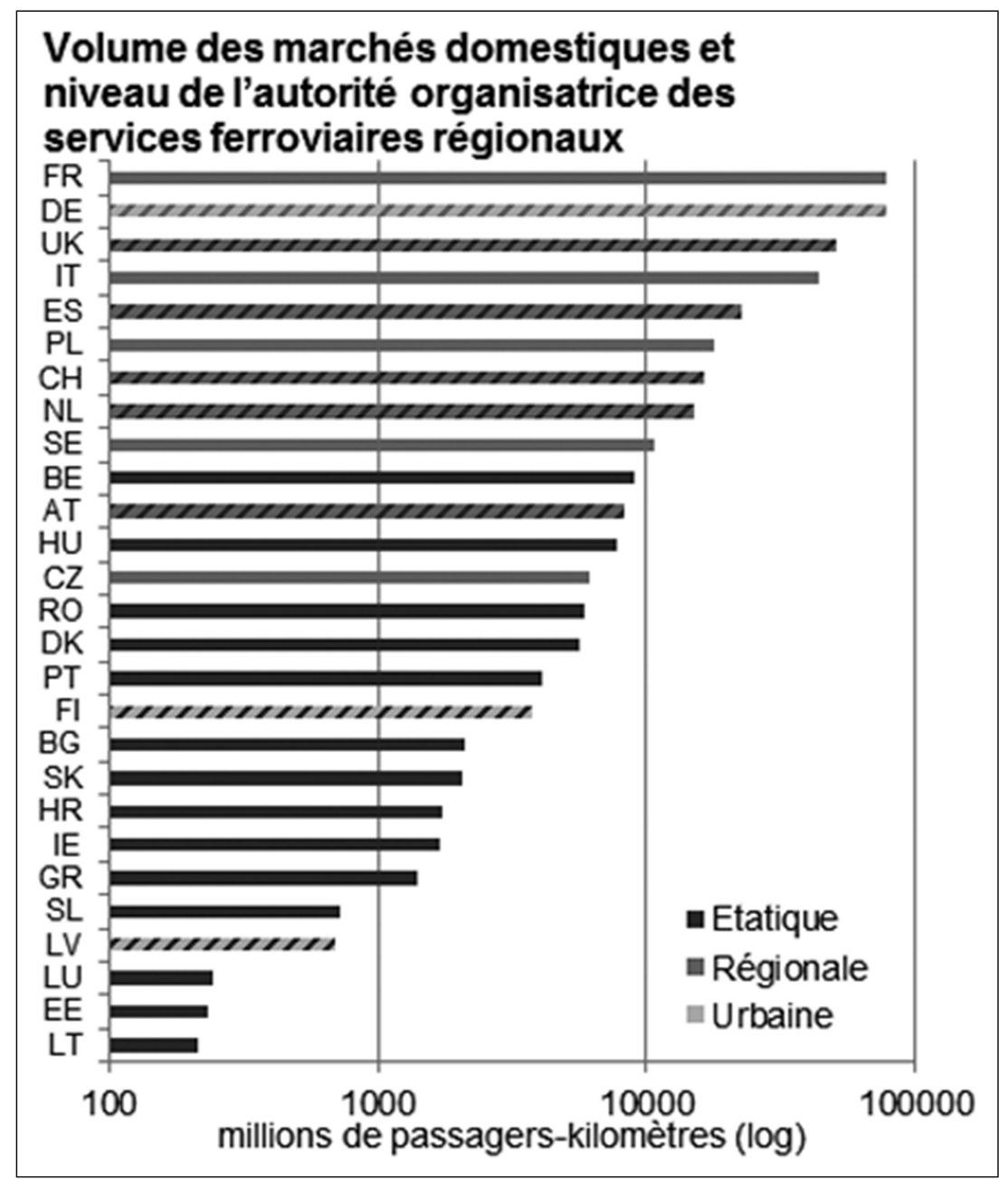

Fig. 4 et 5 Volume des marchés ferroviaires domestiques et niveau de l'autorité organisatrice des services ferroviaires régionaux de voyageurs (données Eurostat 2011). Autorité organisatrice de transport des services ferroviaires régionaux et régionalisation (travaux de l'auteur)

des 153 AOT régionales qui recouvrent les périmètres de plusieurs métropoles ${ }^{3}$.

La définition proposée par la Commission européenne rejoint à première vue la géographie des AOT des services ferroviaires régionaux de voyageurs en Allemagne, composée d'autorités organisatrices de transport régional ou urbain. Bien que plus des deux tiers des AOT soient concernées par cette définition, le lobby représentatif des autorités organisatrices de transport régional en Allemagne, BAG-SPNV, n'émet aucune position.

En France, les régions considèrent que cette définition de l'autorité locale compétente remet en question le principe de subsidiarité. Sept régions métropolitaines recouvrent les périmètres de plusieurs métropoles. Le positionnement

\footnotetext{
${ }^{3}$ Les statistiques sont obtenues à partir des données Eurostat (NUTS 2010 level 2) et de l'audit urbain 2004 qui synthétise l'existence des principaux périmètres de transport urbains.
}

des autorités organisatrices de transport régional en France rejoint ainsi le projet d'avis du Comité des régions, qui propose de revenir à un statu quo ante. Dans ce contexte, l'eurodéputé Mathieu Grosh, rapporteur de la proposition de règlement auprès du comité transport et tourisme du Parlement européen, a également proposé de revenir à la définition actuelle de l'autorité locale compétente.

L'article 2 point e de la proposition de refonte du règlement OSP limite la portée des obligations de service public en excluant « tous les services publics de transport qui ne sont pas strictement nécessaires pour bénéficier des effets de réseau au niveau local, régional ou infranational ». De fait, cette définition, qui remet en question la notion d'effet réseau d'une obligation de service public, a été assouplie par les amendements au Parlement européen.

En France, comme en Europe, les autorités organisatrices de transport régional considèrent que cette notion d'effet 


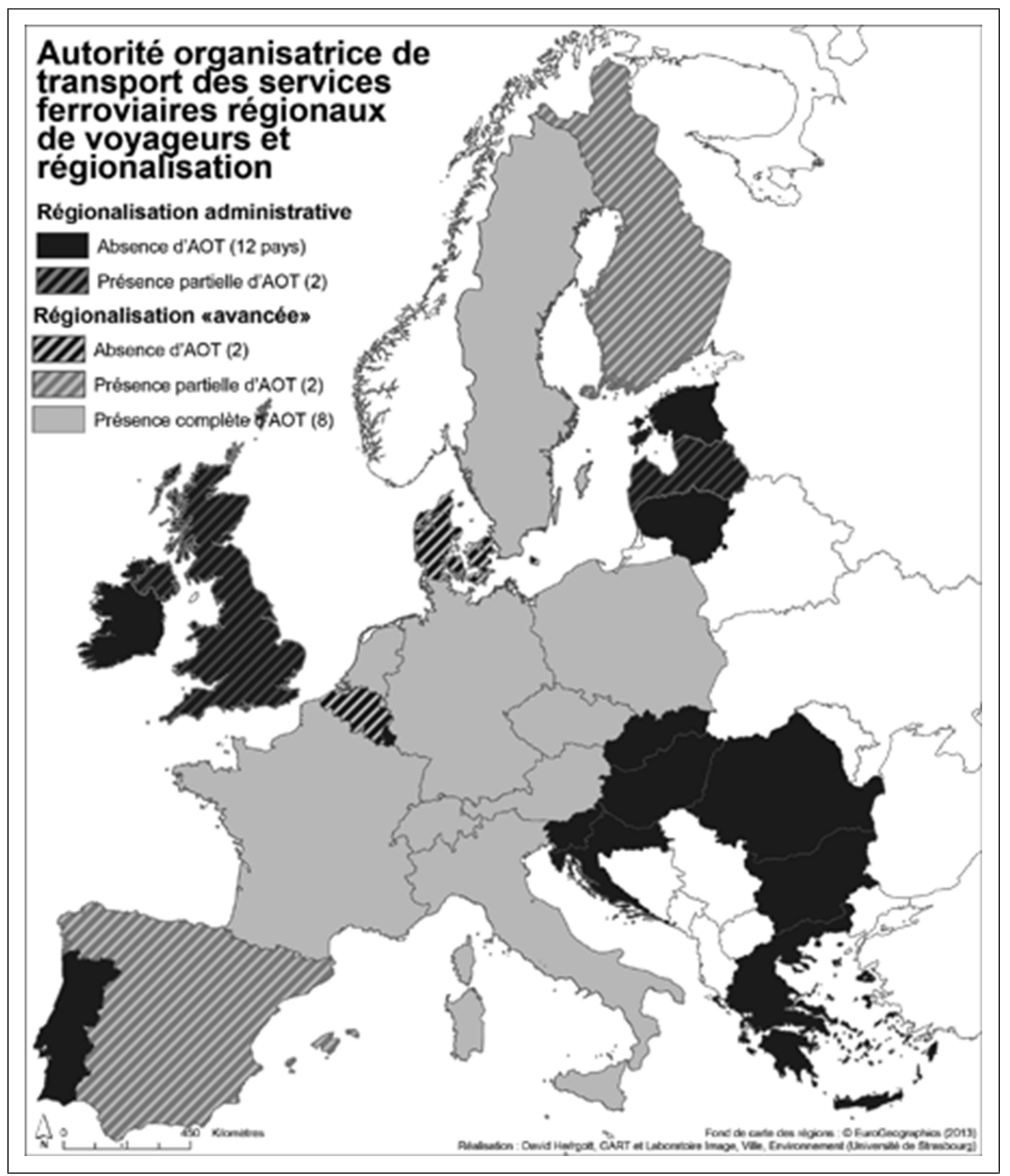

Fig. 4 et 5 (Continued)

réseau ne peut être limitative et doit permettre de maintenir une ligne bénéficiaire ou non au sein d'une obligation de service public. Ces positionnements sont également repris par le projet de rapport du comité transport et tourisme, ainsi que par le projet d'avis du Comité des régions.

L'article 2 bis de la proposition de refonte du règlement OSP créé une limitation des obligations de service public à des volumes maxima, soit « 10 millions de train-km ou un tiers du volume total du transport public national de voyageurs par chemin de fer géré par contrat de service public, la valeur la plus élevée des deux étant retenue ». Cette proposition ne concerne pas les régions françaises Provence-Alpes-Côte d'Azur, Nord-Pas-de-Calais et RhôneAlpes aux trafics annuels respectifs de 12,5, 13,1 et 26,7 millions de trains-kilomètres.
Pour autant, cette proposition se heurte à la réalité géographique des petits pays, qui se verraient obligés de diviser des obligations de services publics supérieures à 10 millions de trains-kilomètres, à défaut de disposer d'un contrat de service public suffisamment important pour représenter un tiers du volume du marché national. Inter Regio Rail propose ainsi de retenir un seuil unique de 25 millions de trains-kilomètres, tandis que le comité transport et tourisme retient la valeur maximale de 35 millions de trains-kilomètres.

Inversement, l'article 5 paragraphe 4 de la proposition de modification du recast permet aux autorités compétentes d'effectuer une attribution directe d'un contrat de service public ferroviaire pour des contrats de moins de 5 millions d'euros ou de moins de 150000 trains-kilomètres. L'écriture 
de cet article se heurte à la réalité des différentiels des coûts d'exploitation entre les États Membres, entre 5 et 12 euros par train $/ \mathrm{km}$ en Allemagne [10], entre 10 et 35 euros par train $/ \mathrm{km}$ en Italie [10], et entre 15 et 26 euros par train $/ \mathrm{km}$ en France ${ }^{4}$. En ce sens, la plupart des lobbies européens proposent de retenir une valeur unique exprimée en trains-kilomètres.

Pour le Comité des régions, le seuil proposé exclut toute ligne ferroviaire sur la base d'un service journalier cadencé (soit un minimum de 7 fréquences par jour et par sens) sur une ligne de l'ordre de 75 kilomètres. Le Comité transport et tourisme, le Comité des régions, ainsi que les organismes représentatifs des autorités organisatrices de transport régional en France proposent de relever ces seuils entre 500000 et 1000000 de trains-kilomètres.

Enfin, l'article 11 de la proposition de modification du recast prévoit la limitation des droits d'accès aux entreprises ferroviaires lorsque l'équilibre économique de contrats de service public est compromis. Les organismes de régulation des activités ferroviaires (tels que l'Autorité de régulation des activités ferroviaires (ARAF) en France), seraient en mesure de déterminer l'existence d'une atteinte à l'équilibre économique d'un contrat de service public, sur demande d'une entreprise ferroviaire, à partir d'éléments transmis par les autorités organisatrices compétentes, le gestionnaire de l'infrastructure ou de l'entreprise ferroviaire exécutant le contrat de service public.

\section{B. Quels financements ?}

La majorité des services ferroviaires régionaux de voyageurs sont financés partiellement ou totalement par des contributions de l'État sur lesquelles les autorités organisatrices de transport régional ne disposent pas de levier d'action (figure 6), décorrélant par conséquent la relation entre contribution publique et coût d'exploitation.

Par exemple, les contributions publiques au financement des services ferroviaires régionaux de voyageurs représentent la plus importante part des contributions publiques aux systèmes ferroviaires français et allemands. Ces contributions représentent 5,4 milliards d'euros sur 14,2 milliards d'euros de contributions publiques en France, et 7,4 milliards d'euros sur 16,3 milliards d'euros de contributions publiques en Allemagne ${ }^{5}$.

La même problématique est observée au niveau de la responsabilité des autorités organisatrices de transport

\footnotetext{
${ }^{4}$ Calcul de l'auteur à partir des données Ville, Rail et Transport 2009 (données 2008). Les coûts d'exploitation en Allemagne et en Italie ont été calculés à partir de l'année 2007.

${ }^{5}$ Calculs de l'auteur dans le cadre des travaux de Fer de France et des articles de Sylvain Seguret [29].
}

régional vis-à-vis de la tarification des services ferroviaires régionaux de voyageurs. Dans dix-sept États membres de l'Union européenne (figure 7), la responsabilité en matière de tarification des services ferroviaires régionaux de voyageurs est plus ou moins sous la coupe de l'État. En France, cette situation conduit les régions françaises à revendiquer une liberté de tarification en dehors des barèmes kilométriques de l'opérateur historique SNCF, et en dehors des tarifs sociaux nationaux [12].

Ainsi, au sein des États membres où les services ferroviaires régionaux de voyageurs sont de la compétence de collectivités locales régionales et/ou urbaines, la tarification n'est de la responsabilité de l'autorité organisatrice de transport régional qu'en Italie et en Suède. Celle-ci est partagée avec l'entreprise ferroviaire en Finlande et en Lettonie, avec l'État en Autriche et en France, et avec l'entreprise ferroviaire et l'État selon les cas en Allemagne. Enfin, elle est la responsabilité de l'entreprise ferroviaire et/ou de l'État en Espagne, aux Pays-Bas, en République Tchèque et au Royaume-Uni.

\section{Quels modes d'attribution des contrats de service public?}

Les paragraphes 2 et 2 bis de l'article 8 de la proposition de refonte du règlement OSP ont pour objectif d'imposer dès le 2 décembre 2019 le principe de l'adjudication pour les obligations de service public. Les autorités organisatrices de transport pourraient faire courir leurs contrats actuels jusqu'au 31 décembre 2022. L'objectif de la Commission européenne est « d'ouvrir progressivement et de manière modulée le transport de passagers à l'échelle nationale » [30], partant du constat que les parts de marché des opérateurs historiques restent prépondérantes au sein des États membres [31].

À l'échelle nationale (figure 8), le marché ferroviaire reste fermé au sein de neuf États membres, bien que la Commission européenne considère que vingt États membres sont de facto dans cette situation [10]. À l'échelle régionale (figure 9), les marchés ferroviaires régionaux sont également fermés et attribués directement à un opérateur au sein de dix États membres en Belgique, Croatie, France, Hongrie, Irlande, Lituanie, Luxembourg, Roumanie, Slovaquie et en Slovénie. Inversement, les marchés ferroviaires régionaux sont progressivement ouverts à la concurrence au sein de seize États membre [2]. Ces derniers sont intégralement ouverts à la concurrence en Bulgarie, Lettonie, Pologne, Royaume-Uni et en Suède, tandis que l'Allemagne, l'Autriche, le Danemark, l'Espagne, l'Estonie, la Finlande, la Grèce, l'Italie, les Pays-Bas, le Portugal et la République tchèque cumulent les deux régimes. 


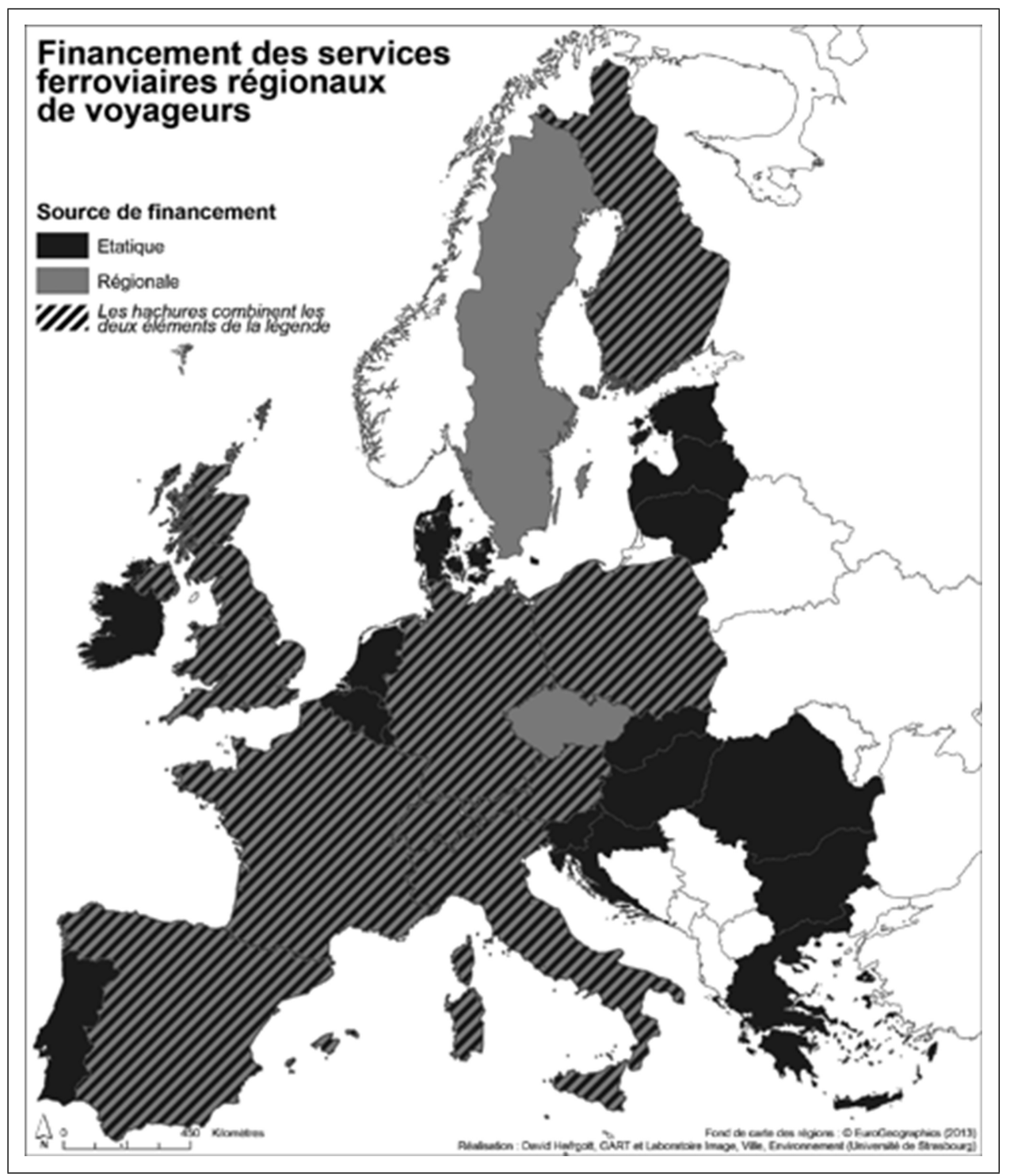

Fig. 6 et 7 Financement et tarification des services ferroviaires régionaux de voyageurs (travaux de l'auteur)

Dans ce contexte, les régions françaises revendiquent principalement « la possibilité de recourir à l'ensemble des choix de mode d'exploitation permis [par l'actuel règlement OSP], à savoir l'exploitation en direct via une régie ou une Société publique locale (SPL), l'attribution directe du contrat à un opérateur ou la mise en concurrence » [12]. Si la proposition de refonte du règlement OSP ne remet pas en question la possibilité offerte aux autorités organisatrices régionales de mettre en place une SPL ou la mise en concurrence, les régions françaises jugent la période de transition insuffisante. Elles rejoignent ainsi les propositions du comité transport et tourisme évoquant une période de transition de 10 ans jusqu'au 3 décembre 2029.

Les amendements votés par le Parlement européen prévoient de décaler au 3 décembre 2022 l'obligation d'adjudication des contrats de service public des services ferroviaires de voyageurs, à l'exception des tram-trains concernés par l'échéance de 2019. Une période de transition est programmée pour une durée de 10 ans à la date d'application du règlement. Cette position va à l'encontre des régions françaises, qui se verraient dans l'obligation de renouveler au moins une fois leurs conventions avec la SNCF sans possibilité d'appel d'offres, seize d'entre elles expirant d'ici 2018 [32].

\section{Quels champs de compétences?}

L'article 2 bis de la proposition de refonte du règlement OSP propose de rendre obligatoire la publication des plans de transports des autorités compétentes. Les contenus de ces 


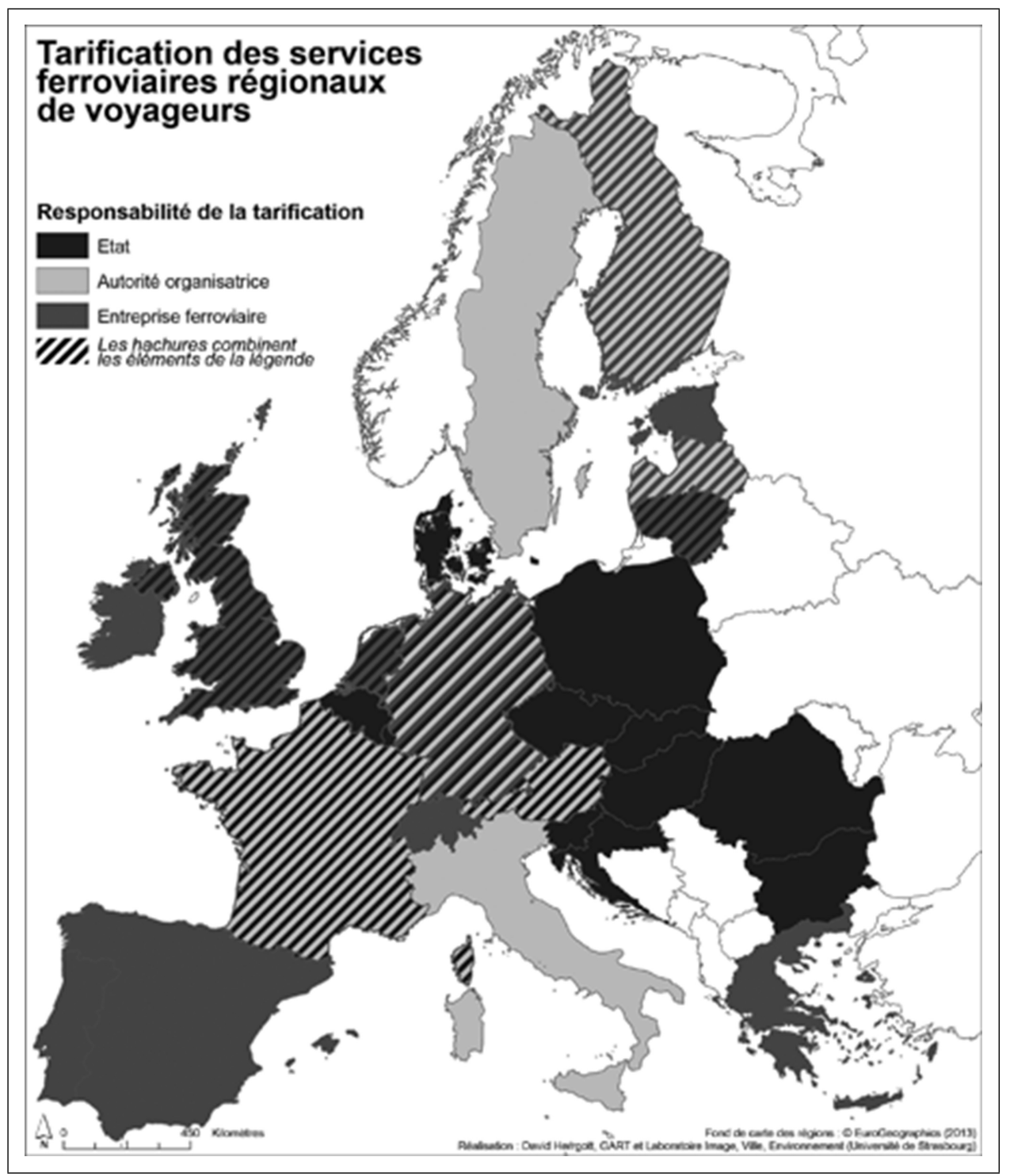

Fig. 6 et 7 (Continued)

plans font également l'objet d'importantes disparités entre les États membres de l'Union européenne.

Ces derniers ont pour objectif de définir la politique du transport public et les moyens de sa mise en œuvre sur le périmètre des AOT. Ces plans de transports intègrent la structure du réseau ; les exigences de base que doit satisfaire l'offre de transport public tels que l'accessibilité, la connectivité territoriale, la sûreté, les interconnexions modales et intermodales; les caractéristiques de l'offre telles que l'horaire d'exploitation, la fréquence des services et le taux minimal d'utilisation ; les normes de qualité relatives aux équipements des arrêts et au matériel roulant, la ponctualité et la fiabilité, la propreté, les services aux usagers et leur information, le traitement des plaintes et les recours, le contrôle de la qualité des services ; les principes de la politique tarifaire ; les exigences opérationnelles telles que le transport de bicyclettes, la gestion du trafic et le plan d'urgence en cas de perturbation.

$\mathrm{Si}$ ces exigences répondent aux revendications des associations d'usagers des transports ${ }^{6}$, la plupart des AOT considèrent ces plans de transports trop exhaustifs par rapport à la vision à moyen/long terme qu'ils sont censés émettre. En ce sens, le comité transport et tourisme a proposé une simplification du contenu des plans limités à la qualité de service, le matériel roulant, l'infrastructure et les services. Le Comité des régions propose également

\footnotetext{
${ }^{6}$ Expression de la Fédération nationale des associations d'usagers des transports (FNAUT) lors de son audition publique le 7 mai 2013 par le comité transport et tourisme.
} 


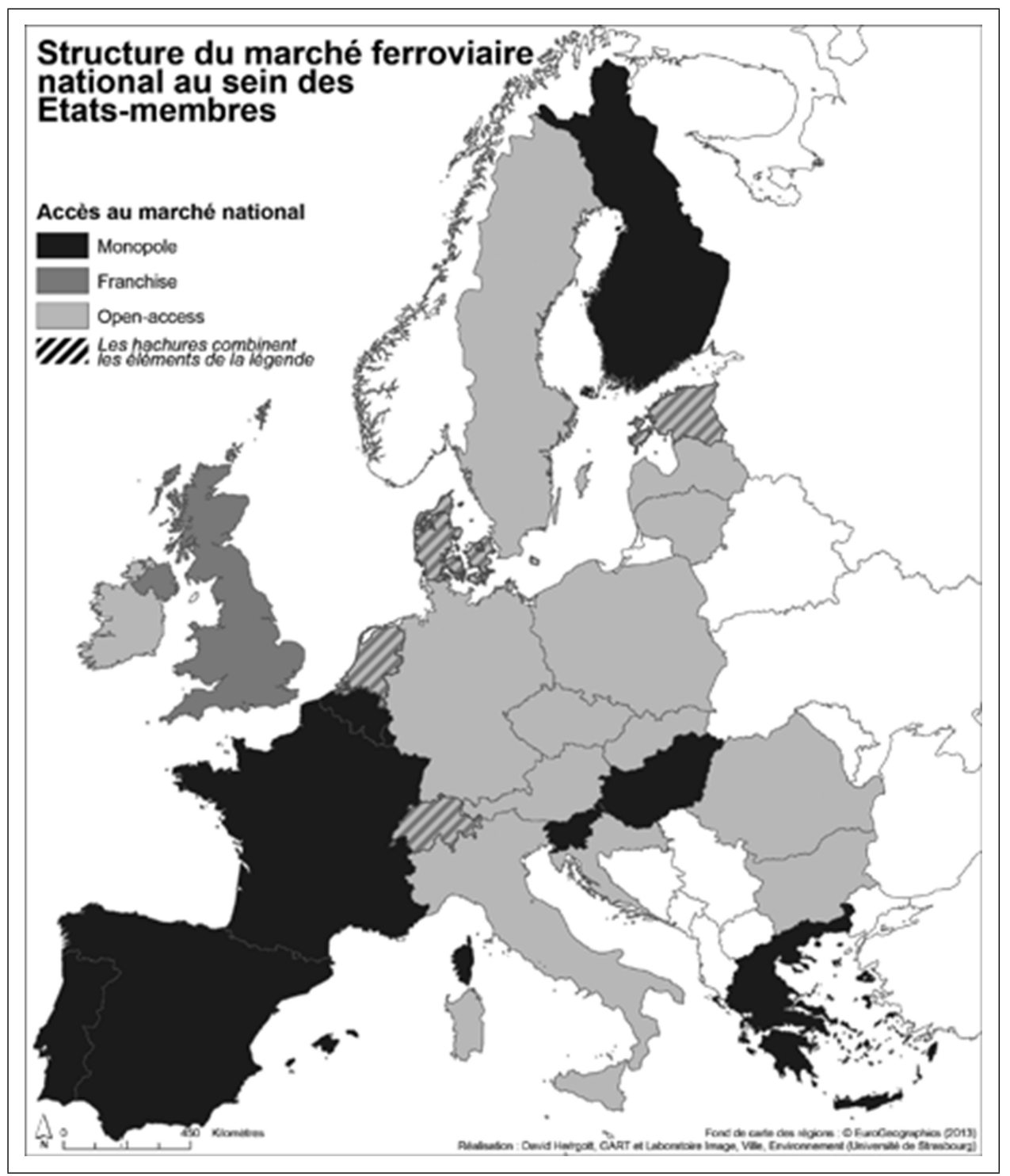

Fig. 8 et 9 Structure du marché ferroviaire national et régional au sein des États membres (travaux de l'auteur)

d'en limiter l'application aux agglomérations de 100000 habitants ou plus.

Le nouvel article 5 bis de la refonte du règlement OSP détermine les conditions d'accès au matériel roulant pour les opérateurs, soit par l'acquisition du matériel roulant par l'autorité locale compétente ou via une société de leasing, soit en apportant une garantie pour le financement du parc ferroviaire et en s'engageant à reprendre le parc ferroviaire au prix du marché à la fin du contrat de service public.

Si ces options conviennent aux autorités organisatrices de transport régional en France, ces propositions se heurtent à l'hétérogénéité de la propriété du matériel roulant au sein des États membres (figure 10). Dans les pays où l'État reste l'autorité compétente des services ferroviaires régionaux de voyageurs, seule l'entreprise ferroviaire dispose de la propriété du matériel roulant. De même, malgré la présence d'autorités organisatrices de transport régional en Autriche, France, Italie, Pologne et en République tchèque, le matériel roulant reste la propriété de l'opérateur. La propriété directe par l'autorité organisatrice de transport régional du matériel roulant n'est que partiellement observée en Allemagne, en Finlande et en Lettonie.

Dans ce cadre, les propositions du Comité des régions, retenues par les amendements du Parlement européen, visent à réduire la portée de la proposition de la Commission Européenne, en élargissant les possibilités d'accès au matériel roulant notamment par la création de pools de matériel entre plusieurs autorités compétentes, l'objectif étant d'y favoriser les économies d'échelle et des montages financiers les plus optimisés. 


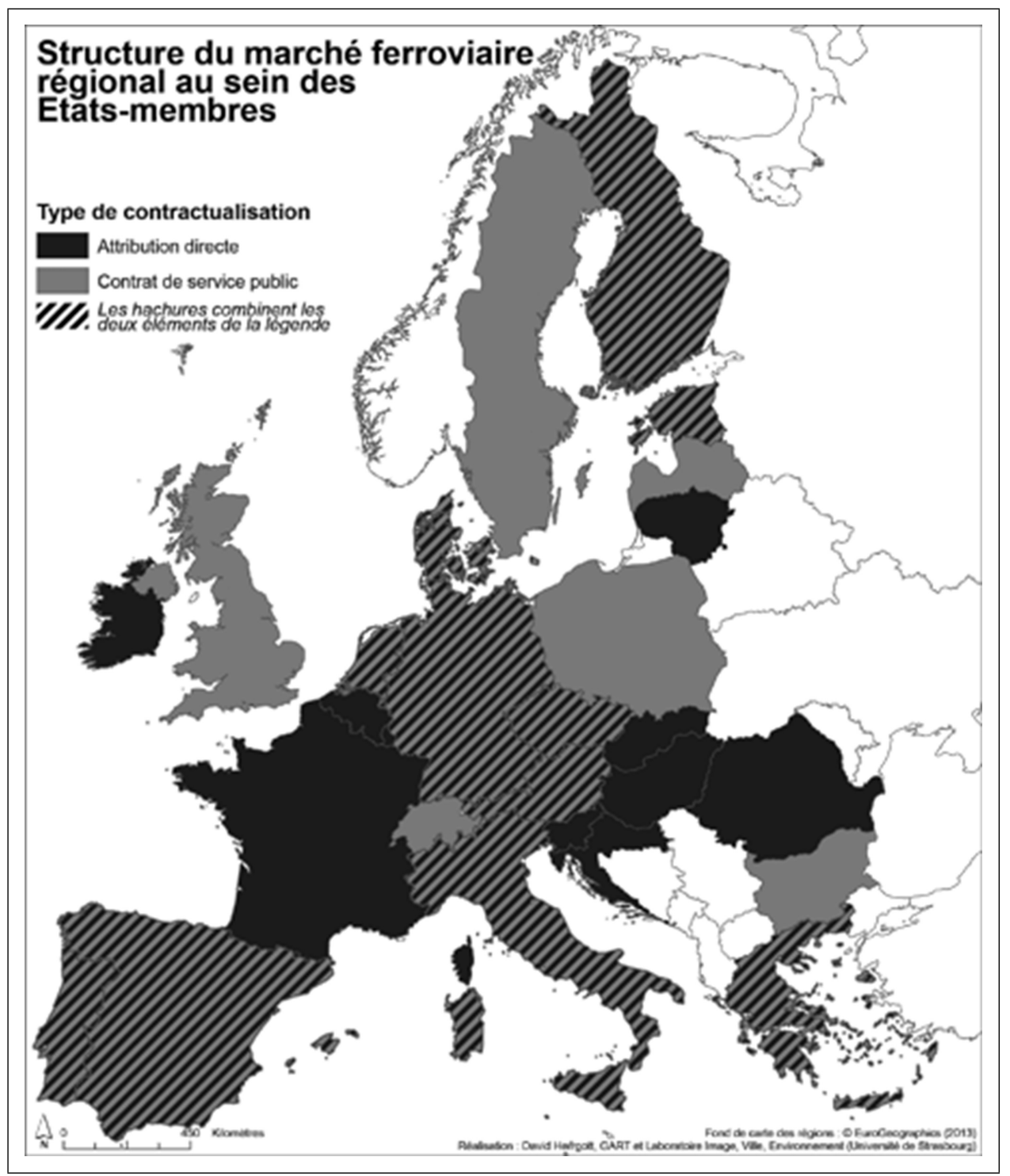

Fig. 8 et 9 (Continued)

Enfin, l'article 13 bis de la proposition de modification du recast permet le développement de système d'information et de billetterie intégrée sur la base du volontariat. Bien que celui-ci soit sur la base du volontariat, Jean-Eric Paquet, ancien directeur de la DG Move, considère cet élément comme une avancée au regard des positions pouvant être exprimées par la DG Concurrence. Seuls quatre États membres disposent aujourd'hui d'un système billettique et d'information plus ou moins intégré en Allemagne, aux Pays-Bas, au Royaume-Uni et en Suède (figure 11).

Pour autant, les propositions du comité transport et tourisme rendent obligatoire le développement de système commun d'information et de billetterie intégrée d'ici le 12 décembre 2020, conformément aux souhaits des autorités organisatrices de transport régional. Pour le Comité des régions, «l'exigence de participation des entreprises opérant des services nationaux à un système d'information national devrait être rendue obligatoire car le développement des services associés est un facteur majeur d'amélioration de l'attractivité des modes de transports collectifs notamment ferroviaires ». Cette mesure n'a été considérée par les eurodéputés qu'applicable pour les services conventionnés de voyageurs.

\section{E. Quels rôles dans la gouvernance des systèmes ferroviaires des États membres?}

Premièrement, l'article 7 quinquies de la proposition de modification du recast prévoit la mise en place de comité de coordination au sein des États membres. Cette proposition 


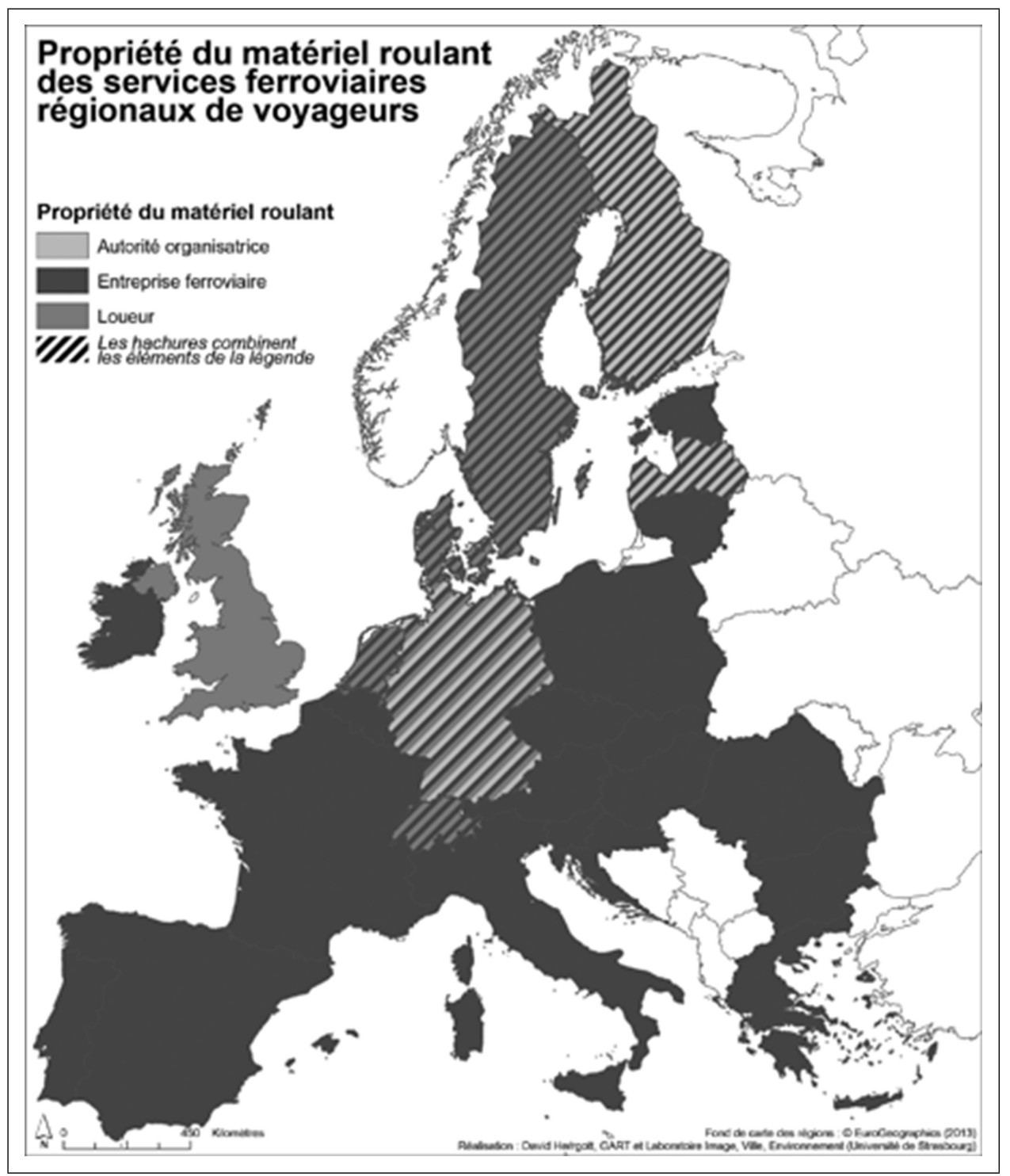

Fig. 10 et 11 Propriété du matériel roulant des services ferroviaires régionaux de voyageurs et fig. 11 Mise en œuvre d'un système d'information et d'un système billettique intégré (travaux de l'auteur)

de la Commission Européenne, dont l'existence formelle n'est aujourd'hui pas observable au sein des États membres, s'inspire de la réforme du ferroviaire en France, à travers la mise en place d'un Haut comité du système de transport ferroviaire [22].

Les autorités organisatrices de transport régional « en tant qu'acteur majeur de la politique des transports, doivent nécessairement faire partie du comité de coordination » selon le Comité des régions.

Deuxièmement, l'article 7 de la proposition de modification du recast, tel qu'amendé par le Parlement européen, limite les modèles de gouvernance en place d'ici son application, sans prendre clairement position pour ou contre le découplage, contrairement à la position initiale de la Commission européenne.
La proposition de la Commission européenne reflète la diversité des organisations ferroviaires au sein des États membres (figure 12), puisque la gestion de l'infrastructure s'effectue directement au sein de l'entreprise ferroviaire historique dans quatre États membres, au sein d'une holding dans sept États membres ${ }^{7}$, et est séparée de l'entreprise ferroviaire historique dans quinze États membres (malgré un lien très fort avec la gestion d'infrastructure déléguée à l'entreprise ferroviaire historique en Finlande, en France et aux Pays-Bas).

\footnotetext{
${ }^{7} \mathrm{Au} 1^{\mathrm{er}}$ janvier 2015, la France passe d'une gestion de l'infrastructure séparée de l'entreprise ferroviaire historique à une gestion de l'infrastructure au sein d'une holding.
} 


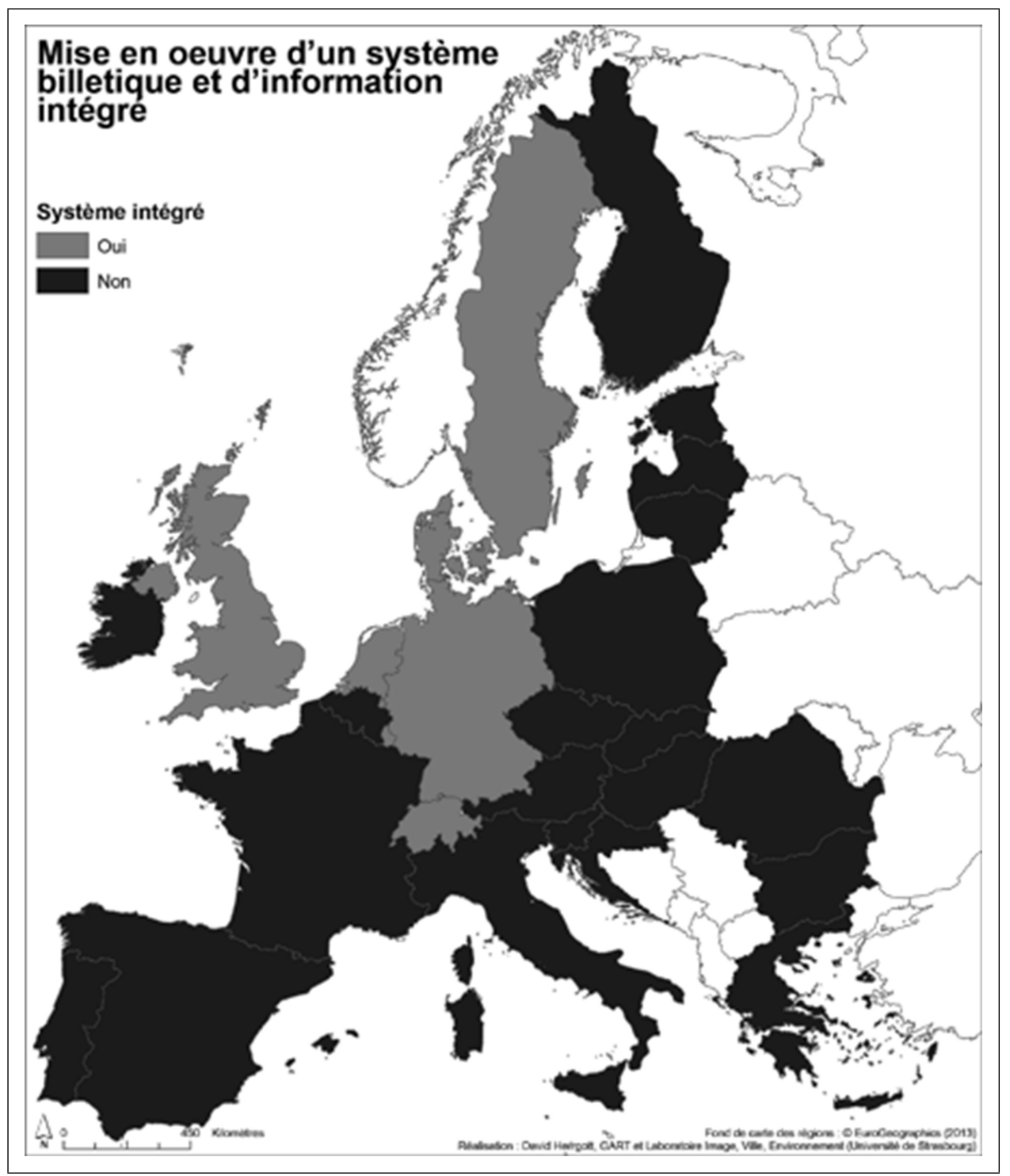

Fig. 10 et 11 (Continued)

Si la gestion de l'infrastructure ne concerne pas directement les autorités organisatrices de transport régional, le Comité des régions rappelle leurs nécessaires participations « aux instances de décisions ou de contrôle du gestionnaire d'infrastructure qui bénéficie d'un monopole naturel ». Les autorités organisatrices de transport régional sont ainsi identifiées comme «le lien entre les opérateurs et les utilisateurs finaux dont elles connaissent les besoins ».

La proposition permet ainsi aux autorités organisatrices de transport régional d'être présentes au sein des structures de gouvernance des gestionnaires de l'infrastructure, condition nécessaire dans le cas de possibles expérimentations de gestion et d'exploitation unique sur des petites lignes pour des services voyageurs ou fret. À ce titre, le Comité des régions propose des dérogations pour les petits réseaux ferroviaires, short-liners et projets d'investissements spécifiques.

Toutefois, si la proposition de directive est très précise sur la gouvernance de la gestion de l'infrastructure, elle ne précise en rien les conditions de la gouvernance des gares, dont le mode d'organisation, très hétérogène au sein des États membres, diffère de la gestion de l'infrastructure (figure 13).

En effet, lorsque la gestion de l'infrastructure s'effectue au sein de l'entreprise ferroviaire historique, la gestion des gares est également une compétence de l'entreprise ferroviaire historique en Irlande, en Lituanie, au Luxembourg et en Slovénie. Lorsque la gestion de l'infrastructure s'effectue au sein d'une holding, la gestion des gares est une compétence du gestionnaire d'infrastructure en 


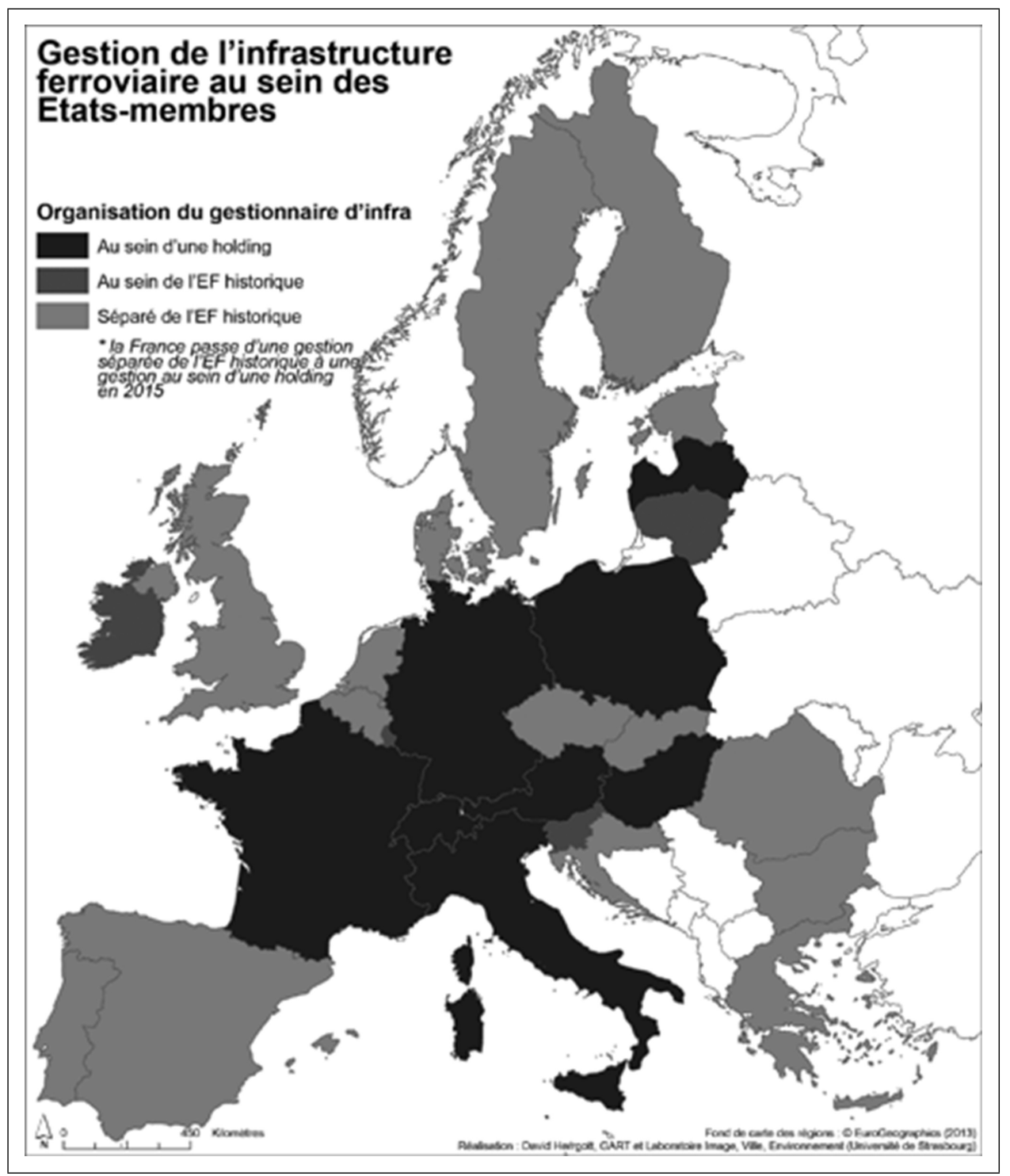

Fig. 12 et 13 Gestion de l'infrastructure et gestion des gares au sein des États membres (travaux de l'auteur)

Allemagne et en Autriche et de l'entreprise ferroviaire historique en Hongrie, en Italie, en Lettonie et en Pologne. Enfin, lorsque la gestion de l'infrastructure est séparée de l'entreprise ferroviaire historique, la gestion des gares reste une compétence de l'entreprise ferroviaire historique au Danemark, en Estonie, en Finlande, en France, en Grèce, aux Pays-Bas et en République tchèque, et est au sein du gestionnaire de l'infrastructure en Belgique, Bulgarie, Croatie, Espagne, Portugal, Roumanie, Slovaquie et en Suède. Au Royaume-Uni, la gestion des gares est partagée entre le gestionnaire d'infrastructure et les entreprises ferroviaires dans le cas de certaines gares régionales.

\section{Conclusion}

Le long processus de réforme ferroviaire en Europe se heurte largement au poids de l'héritage des contextes nationaux qui en ont fixé la logique technique et identitaire pendant de longues décennies [2]. Pour autant, la construction d'un espace ferroviaire unique européen à l'échelle des services ferroviaires régionaux de voyageurs se heurte également à la réalité de la construction des institutions politiques locales au sein des États membres. Seule l'attribution d'une relative autonomie aux institutions locales permet l'existence d'autorités organisatrices de transport régional. 


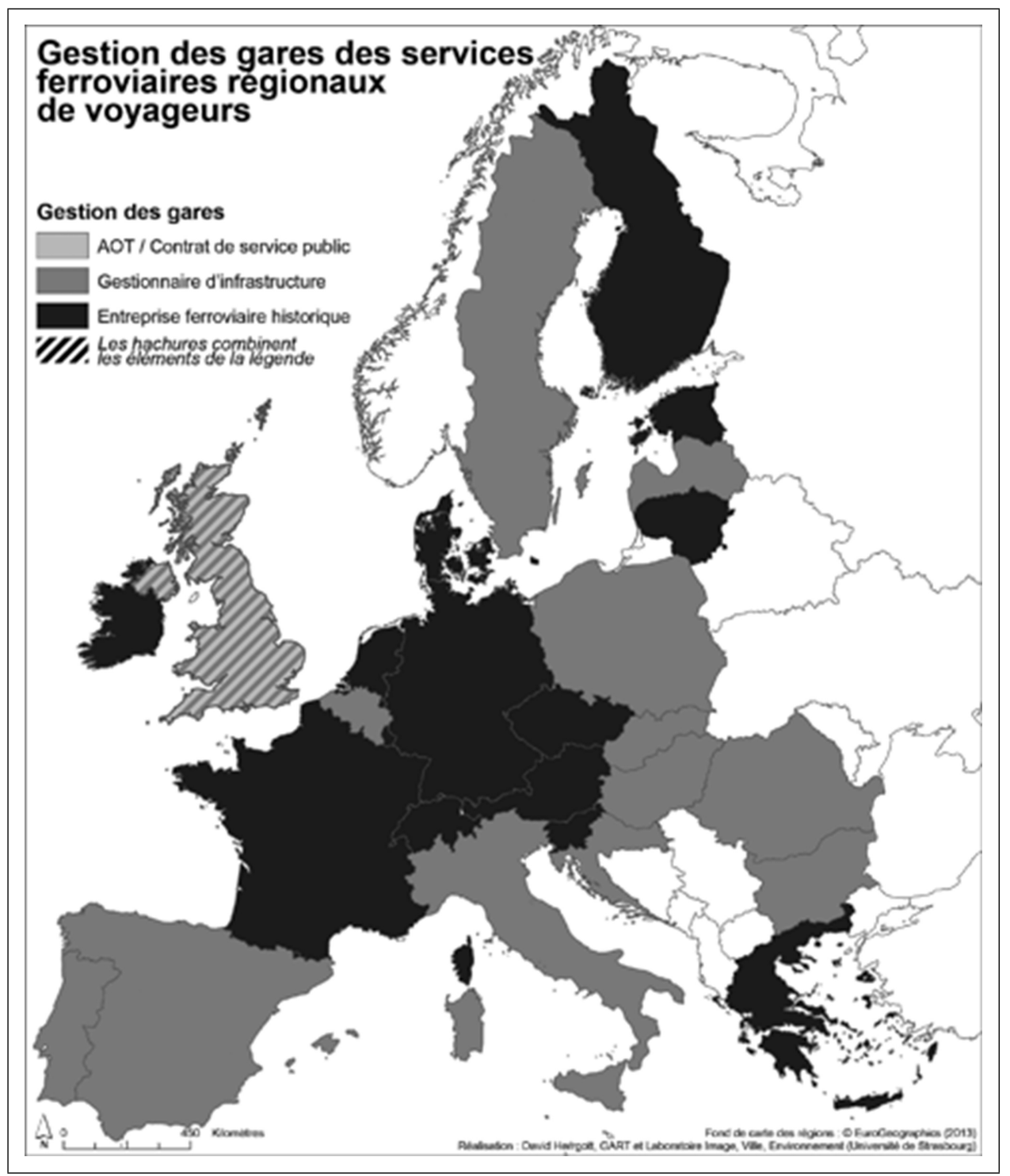

Fig. 12 et 13 (Continued)

Ainsi, les compétences des autorités organisatrices de transport régional restent bien disparates au sein des huit États membres les reconnaissant pleinement. Par exemple, au sein de ces huit États membres, seules les autorités organisatrices de transport régional en République tchèque et en Suède disposent de ressources propres pour le financement de leurs services ferroviaires régionaux de voyageurs, seules les autorités organisatrices de transport régional en Italie et en Suède disposent de la pleine responsabilité en matière de tarification, et seules certaines autorités locales compétentes en Allemagne maîtrisent la propriété de leur matériel roulant, condition nécessaire à la liquidité de ces concessions de service public à forte concentration capitalistique.

Outre les possibles réticences des États membres au développement de l'autonomie des institutions locales, les
AOT régionales se heurtent également à la réticence des entreprises ferroviaires historiques. Aucun État membre au marché ferroviaire national fermé n'a été en mesure d'accorder une liberté du choix de mode de contractualisation aux autorités organisatrices régionales présentes sur son territoire. De cette manière, le marché ferroviaire régional n'est ouvert que dans le cas de la Pologne et de la Suède, et partiellement ouvert en Allemagne, en Autriche, en Italie, aux Pays-Bas et en République tchèque.

La généralisation du processus d'adjudication, qui peut conduire à de substantiels gains pour la collectivité [33], se heurtera-t-elle ainsi à l'hétérogénéité des situations locales ? Le vote par le Parlement européen le 25 février 2014 d'un principe de réciprocité, limitant l'accès aux marchés européens aux entreprises ferroviaires historiques dont le marché national est ouvert à la concurrence, traduit 
bien la crispation du législateur face à l'hétérogénéité des situations locales. La construction de l'espace ferroviaire unique européen nécessitera également une harmonisation du rôle des autorités organisatrices de transport des services ferroviaires régionaux de voyageurs.

\section{Références bibliographiques}

1. Commission Européenne (2001) La politique Européenne des transports à l'horizon 2010: l'heure des choix, Livre blanc de la Commission européenne, Bruxelles, $135 \mathrm{p}$.

2. Beyer A, Chabalier D (2009) La réforme ferroviaire en Europe in : Savy M, Questions pour le transport en Europe. La Documentation Française, Paris, pp 997-116.

3. Ollivier-Trigalo M (2007) Six régions à l'épreuve des politiques de transport. Inrets, Paris, $233 \mathrm{p}$.

4. Commission européenne (2007) Vers une nouvelle culture de la mobilité urbaine, Livre vert de la Commission européenne, Bruxelles, $6 \mathrm{p}$.

5. CERTU (2001) La régionalisation des transports ferroviaires, Rapport d'étude ENTPE/CERTU, Lyon, 120 p.

6. Faure A (2007) Doctrine ferroviaire et différenciation régionale : la décentralisation en chantier in Ollivier-Trigalo M, Six régions à l'épreuve des politiques de transport. Inrets, Paris, pp 55-72.

7. Commission européenne (2013) Proposition de directive modifiant la directive 2012/34/UE du Parlement européen et du Conseil du 21 novembre 2012 établissant un espace ferroviaire unique européen, en ce qui concerne l'ouverture du marché des services nationaux de transport de voyageurs par chemin de fer et la gouvernance de l'infrastructure ferroviaire, $\operatorname{COM(2013)~} 29$ final, Commission européenne, Bruxelles, $21 \mathrm{p}$.

8. Commission européenne (2013) Proposition de règlement modifiant le règlement (CE) $n^{\circ}$ 1370/2007 en ce qui concerne l'ouverture du marché des services nationaux de transport de voyageurs par chemin de fer, COM(2013) 28 final, Commission européenne, Bruxelles, $17 \mathrm{p}$.

9. Commission européenne (2011) Feuille de route pour un espace européen unique des transports - Vers un système de transport compétitif et économe en ressources, Livre blanc de la Commission européenne, Bruxelles, $35 \mathrm{p}$.

10. European commission (2013) Impact assessment accompanying the document COM(2013) 28 final and COM(2013) 29 final, European Commission, Bruxelles, $116 \mathrm{p}$.

11. Fontgalland $\mathrm{B}$ (1980) Le système ferroviaire à travers le monde, Éditions CELSE, Paris, 209 p.

12. ARF (2011) Manifeste des transports régionaux, Association des Régions de France, Paris, 9 p.

13. EMTA (2013) La position de l'EMTA concernant la Proposition de modification du Règlement 1370/07 dans le cadre du $4^{\mathrm{e}}$ Paquet ferroviaire, Édition de l'EMTA, Bruxelles, 6 p.

14. Comité des régions (2013) Projet d'avis de la commission de la politique de cohésion territoriale quatrième paquet ferroviaire, COTER, Bruxelles, $30 \mathrm{p}$.
15. Inter regio rail (2010) Regional Passenger Rail Transport in Europe-An Overview and Comparison of Organisation and Responsibilities, Inter Regio Rail, Berlin, $136 \mathrm{p}$.

16. ARF (2013) Note de positionnement de l'ARF sur la proposition de 4e paquet ferroviaire publiée par la Commission européenne le 30 janvier 2013, Association des Régions de France, Paris, 6 p.

17. GART (2013) Position du GART sur le $4^{\mathrm{e}}$ paquet ferroviaire, Groupement des Autorités Responsables de Transport, Paris, 4 p.

18. CESE (2013) Document de travail de la section spécialisée « Transports, énergie, infrastructures, société de l'information » sur le « $4^{\mathrm{e}}$ paquet ferroviaire », Édition du Conseil économique et social européen, Paris, $10 \mathrm{p}$.

19. Inter regio rail (2013) Position of European passenger rail authorities on the Fourth railway package proposal - draft, Inter Regio Rail, Berlin, $41 \mathrm{p}$.

20. SETRA (2009) Le transport ferroviaire de voyageurs sur le réseau ferré national français, Exploration d'un système complexe, MEEDDM, Paris, $90 \mathrm{p}$.

21. CAS (2011) L'ouverture à la concurrence du transport ferroviaire régional de voyageurs, Rapports et documents du Conseil d'Analyse Stratégique, Paris, $122 \mathrm{p}$.

22. Bianco J-L, Sardais C, Espinasse L (2013) Réussir la réforme du système ferroviaire, Rapport d'information, Paris, $22 \mathrm{p}$.

23. Guihery L (2005) Régionalisation ferroviaire et convention Régions-SNCF : quels enjeux et quelles perspectives ? Pouvoirs Locaux 66:55-59

24. Ineco (2012) Definición de los servicios ferroviarios de media distancia que se regirán por obligaciones de servicio público y análisis intermodal por corredores de los servicios de transporte de viajeros de media distancia por ferrocarril y carretera, Ministerio de fomento del Gobierno de España, Madrid, 397 p.

25. Kahl A (2005) Der öffentliche Personennahverkehr auf dem Weg zum Wettbewerb. Institut fur öffentliches Rech, Finanzrecht und Politikwissenschaft der Universität Innsbruck, Innsbruck, $551 \mathrm{p}$.

26. GART-ADCF (2013) Transports et déplacements, du transfert à l'exercice de la compétence en 40 questions-réponses, Étude GART-ADCF, Paris, $32 \mathrm{p}$.

27. Goethals C (2010) Les transports publics urbains en Belgique. CIRIEC 2010(11) : 1-48.

28. Marcou G (1999) La régionalisation en Europe - Rapport du Parlement européen, Groupement de Recherches sur l'Administration Locale en Europe, Paris, $170 \mathrm{p}$.

29. Seguret S (2007) Les contributions publiques au financement des systèmes ferroviaires en France et en Allemagne. Transports 444: 223-231.

30. Paquet J-E (2013) Présentation du $4^{\mathrm{e}}$ paquet ferroviaire, Communication de la Commission européenne auprès de sa représentation française, 7 février 2013.

31. Goujon S (2004) Le transport ferroviaire en Europe, les étapes de la libéralisation. SES 151:1-8.

32. ARF (2014) Manifeste des Régions pour le renouveau du système ferroviaire, Association des Régions de France, Paris, $12 \mathrm{p}$.

33. Crozet Y, Desmaris C (2011) Le transport ferroviaire régional de voyageurs : un processus collectif d'apprentissage. Recherche Transports Sécurité 27 : 143-162. 